\title{
Geographical and ethnic distribution of single nucleotide polymorphisms within genes of the folate/homocysteine pathway metabolism
}

\author{
Aristea Binia - Alejandra V. Contreras • \\ Samuel Canizales-Quinteros • Victor Acuña Alonzo • \\ M. Elizabeth Tejero• Irma Silva-Zolezzi
}

Received: 17 April 2014/ Accepted: 25 July 2014/Published online: 9 August 2014

(C) The Author(s) 2014. This article is published with open access at Springerlink.com

\begin{abstract}
High levels of plasma homocysteine are associated with an increased risk of many health conditions influenced by both environmental and genetic factors. The objective of this study was to provide the geographical distribution of folate pathway genetic polymorphisms in Mexico and the comparison with the reported frequencies in different continental populations. This study included the analysis of the genotypic frequencies of eight polymorphisms in genes of the folate/homocysteine metabolic pathway in 1,350 Mestizo and Amerindian subjects from different regions in Mexico and 836 individuals from
\end{abstract}

Aristea Binia and Alejandra V. Contreras equally contributed to this work.

Electronic supplementary material The online version of this article (doi:10.1007/s12263-014-0421-7) contains supplementary material, which is available to authorized users.

A. Binia $(\bowtie) \cdot$ I. Silva-Zolezzi

Nutrition and Health Research, Nestlé Research Center,

Lausanne, Switzerland

e-mail: aristea.binia@rdls.nestle.com

A. V. Contreras - M. E. Tejero

Laboratorio de Nutrigenética y Nutrigenómica,

Instituto Nacional de Medicina Genómica (INMEGEN),

Mexico City, Mexico

S. Canizales-Quinteros

Unidad de Genómica de Poblaciones Aplicada a la Salud, Facultad de Química, Universidad Nacional Autónoma de México (UNAM)-INMEGEN, Unidad de Biología Molecular y Medicina Genómica, Instituto Nacional de Ciencias Médicas y Nutrición "Salvador Zubirán” (INCMNSZ), Mexico City,

Mexico

V. A. Alonzo

Escuela Nacional de Antropología e Historia (ENAH),

Molecular Genetics Laboratory, Mexico City 14030, Mexico
European, African and Asian populations of the 1,000 Genomes Project. In Mexican Mestizo and Amerindian populations, the MTHFR C677T risk genotype (TT) was highly prevalent (frequency: 25 and $57 \%$, respectively). In Mestizos, the frequency showed clear regional variation related to ancestry; the Guerrero subpopulation with the highest Amerindian contribution had the highest TT frequency ( $33 \%$ ). The MTHFDI G1958A AA risk genotype was also enriched in Mexican Mestizos and Amerindians (frequency: 34 and $58 \%$, respectively), whereas in African and Asian ancestry populations the frequency for AA was low $(\sim 4 \%)$. All together risk genotypes showed regional differences, and Sonora had significantly different genetic frequencies compared with the other regions $(P$ value $<0.05)$. Our study illustrates differential geographical distribution of the risk variants in the folate/ homocysteine metabolic pathway relative to ethnic background. This work supports that certain areas of the world have increased needs for folic acid and vitamin B supplementation, and this information needs to be considered in public health guidelines and eventually policies.

Keywords Folate - Homocysteine $\cdot M T H F D 1$ G1958A MTRR A66G $\cdot$ MTHFR A1298C $\cdot$ MTHFR C677T

\section{Introduction}

Folates are a group of molecules that belong to the vitamin B family, differing by their oxidation state, number of glutamic acid moieties and one-carbon substitutions (Forges et al. 2007). They are part of the commonly known folate-mediated one-carbon metabolism pathway, a system consisting of a number of interdependent metabolic cycles, that are necessary in a large number of biochemical 
processes, such as amino acid metabolism, purine and pyrimidine synthesis and methylation of nucleic acids, proteins and lipids (Forges et al. 2007; Carr et al. 2009). The folate-mediated one-carbon metabolism pathway is essential for human health and development, which is made evident by the fact that folate deficiency has been linked to a variety of conditions along the life span including adverse pregnancy outcomes such as neural tubes defects (NTDs). Hyperhomocysteinemia a known risk factor to a range of conditions, such as cardiovascular and neurodegenerative disorders, has also been associated with this metabolic pathway (Forges et al. 2007). Folic acid supplementation during the periconceptional period reduces greatly the risk of NTDs (Prevention of neural tube defects: results of the Medical Research Council Vitamin Study. MRC Vitamin Study Research Group 1991), and many countries have now mandatory fortification legislation and programs in place to avert the disease risks linked to folate deficiencies (Wolff et al. 2009; Berry et al. 1999). In Latin America, following the implementation of folic acid fortification, NTDs prevalence was decreased from 33 to $59 \%$ (Rosenthal et al. 2013). However, the benefit of folic acid supplementation in reducing the risk for cardiovascular diseases (CVD) by decreasing the homocysteine levels is not clear, revealing a more complex relationship between vitamin intake levels, homocysteine and CVD (Bonaa et al. 2006; Homocysteine Studies 2002; Toole et al. 2004; Lonn et al. 2006).

Several studies have identified associations between polymorphisms in genes related to the folate pathway (Fig. 1), some of them with known functional implications, and specific conditions, including NTDs, CVD, psychiatric disorders and some types of cancers, such as colorectal, pancreatic, gastric and ovarian (Berry et al. 1999; Greene et al. 2009; Gueant-Rodriguez et al. 2006; Fredriksen et al. 2007; Koushik et al. 2006; Lissowska et al. 2007). However, there is evidence that shows no effects or conflicting findings about these associations of genetic variants of folate metabolism (Ding et al. 2013; Stevens et al. 2008; Sharp and Little 2004; Zhou et al. 2012; Yu et al. 2010). One problem in the meta-analyses of genetic association studies is the scarcity of data sets that would allow for the analysis of covariates (Jennings and Willis 2014); consequently, the metabolic effects associated with altered onecarbon metabolism of these diseases require extensive investigations.

In relation to polymorphisms in genes functionally related to this pathway, as of today, only some have been analyzed in case-control and/or in epidemiological studies in different populations. Some of these extensively studied are within the methylenetetrahydrofolate reductase gene $(M T H F R)$, which encodes for an enzyme catalyzing the irreversible reduction of 5, 10-methylenetetrahydrofolate to 5-methyltetrahydrofolate serving as the methyl donor for the vitamin- $B_{12}$-dependent remethylation of homocysteine (Hcy) to methionine (Fig. 1) (Frosst et al. 1995). These polymorphisms are the MTHFR C677T (A222V, rs1801133) and A1298C (E429A, rs1801131), both known to result in a decreased activity of the enzyme (Frosst et al. 1995; Weisberg et al. 1998). In addition to these functional polymorphisms, other genetic variants within coding regions of related genes in this pathway have been found to be associated with a variety of complex traits and disorders, including the methionine
Fig. 1 Metabolic cycle of homocysteine, the seven enzymes carrying the functional SNPs analyzed in the study are shown in red (SAM S-Adenosyl methionine, $S A H S$-Adenosyl-Lhomocysteine, BHMT Betainehomocysteine

S-methyltransferase, $C B S$ Cystathionine beta synthase, FOLH1 Folate hydrolase, MTHFD1

Methylenetetrahydrofolate dehydrogenase 1, MTHFR Methylenetetrahydrofolate reductase, MTRR Methionine synthase reductase, MTR Methionine synthase, SLC19A1 Solute carrier family 19, TCN2 Transcobalamin II)

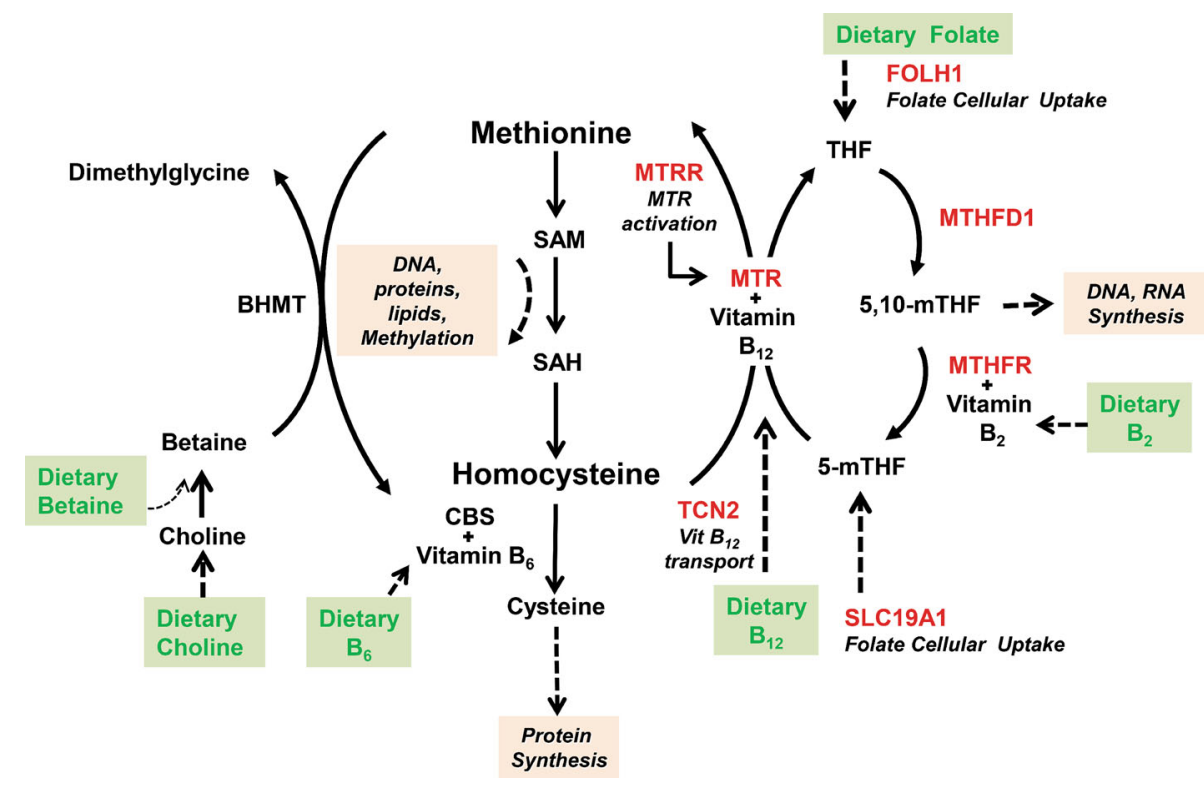


synthase reductase MTRR A66G, the methionine synthase or 5-methyltetrahydrofolate-homocysteine methyltransferase MTR A2756G, the methylenetetrahydrofolate dehydrogenase 1 MTHFDl G1958A, the folate hydrolase FOLH1 T484C, the solute carrier family 19 (folate influx transporter) member 1 SLC19A1 A80G and the transport protein of vitamin $\mathrm{B}_{12}$, transcobalamin II TCN2 C776G (Gaughan et al. 2001; Lissowska et al. 2007; Silva et al. 2011; Guo et al. 2013; Xie et al. 2012; Dervieux et al. 2004b; Laverdiere et al. 2002; Martinelli et al. 2006; Moskau et al. 2007; Parveen et al. 2013). The frequencies of some of these polymorphisms are known to vary across different geographical regions and ethnic groups. For example, the MTHFR 677TT genotype frequency is often reported to be high in European, Asian, Central and South American (10-32\%), low in different African populations (0-3\%) (Wilcken et al. 2003) and also showing geographical gradients among Chinese Han populations (Yang et al. 2013). The possibility of having accurate information about the frequency of these polymorphisms and better understanding of their variation between and within populations can help experts in this field improve the design of association studies, aid in the evaluation of regional dietary requirements and inform public health policy makers.

The Mexican population is mainly composed by Mestizos, who are individuals with a genetic background consisting of Amerindian, European and, to a lesser extent, African ancestries, and as a result of admixture, the resulting linkage disequilibrium patterns in all these genetic loci may affect the allele frequencies (Silva-Zolezzi et al. 2009). This population has been reported to have one of the highest frequencies of the MTHFR 677T allele worldwide, above to that reported in some European and African populations (Wilcken et al. 2003), suggesting that this results due to an enrichment of this variant in Mexicans through the admixture process and the Amerindian ancestral contribution. To better understand the distribution of this and other variants in the folate-mediated one-carbon metabolism pathway in a highly admixed population such as Mexicans, we describe and compare the allele and genotype frequencies of FOLH1 T484C, MTR A2756G, MTHFD1 G1958A, MTRR A66G, MTHFR A1298C, MTHFR C677T, SLC19A1 A80G and TCN2 C77G (Fig. 1; Suppl. Table 1) in 1,104 Mexican Mestizos from the Mexican Genome Diversity Project (MGDP), 246 subjects with Amerindian ancestry and 836 samples from Phase I, 1,000 Genomes Project, from distinct continental locations, and/or ancestral contributions, including African, Asian and European.

\section{Methods}

Samples

DNA samples included in this study are from 1,104 adult Mexican Mestizos (MEX) from the Mexican Genome Diversity Project (MGDP) (Silva-Zolezzi et al. 2009), corresponding to 184 unrelated individuals (92 males and 92 females) from each of six different states of Mexico: Sonora (SON), Guanajuato (GUA), Zacatecas (ZAC), Guerrero (GUE), Veracruz (VER) and Yucatan (YUC). In addition, we included samples from three Amerindian groups (AMI), 172 Nahuas (NAH), 49 Zapotecos (ZAP) and 25 Totonacas (TOT) (Fig. 2). All individuals in the Amerindian groups, their parents and grandparents recognized themselves as indigenous, had been born and lived in their home communities and spoke their native language. This study was conducted according to the principles expressed in the Declaration of Helsinki. All the participants of the MGDP and the Amerindian groups signed a consent approved by the Scientific, Ethics and Biosafety Review Boards from the National Institute of Genomic Medicine (INMEGEN) and the National Institute of Medical Sciences and Nutrition Salvador Zubirán (INCMNSZ), respectively. The genotypic and allelic frequencies analysis of this study was approved by the Ethics committee as previously reported (Contreras et al. 2014; Silva-Zolezzi et al. 2009; Leon-Mimila et al. 2013). No phenotypic data of the subjects were available or analyzed. DNA was isolated from buffy coats obtained from blood using the QIAamp DNA Blood Maxi Kit (Qiagen GmbH, Hilden, Germany).

\section{Genotyping}

We analyzed eight SNPs, MTHFR C677T and A1298C, MTR A2756G, MTRR A66G, MTHFD1 G1958A, TCN2 C776G, FOLH1 T484C and SLC19A1 A80G, by allelic discrimination with TaqMan ${ }^{\circledR}$ SNP genotyping assays (Applied Biosystems, Life Technologies CA, USA), according to the manufacturer's protocol. We used $15 \mathrm{ng}$ of genomic DNA as template, the assays run on 7900HT PCR Real Time System (Applied Biosystems, Life Technologies CA, USA) and then analyzed using the Sequence Detection System v2.2.2. To verify the accuracy of the genotyping, we compared our data with the genotypes for all SNPs, except MTRR A66G, obtained for a subset of 296 individuals from the Mexican Mestizos group by using Illumina $550 \mathrm{~K}$ (Moreno-Estrada et al. 2014) and $510 \mathrm{~K}$ arrays (Illumina Inc., CA, USA). 


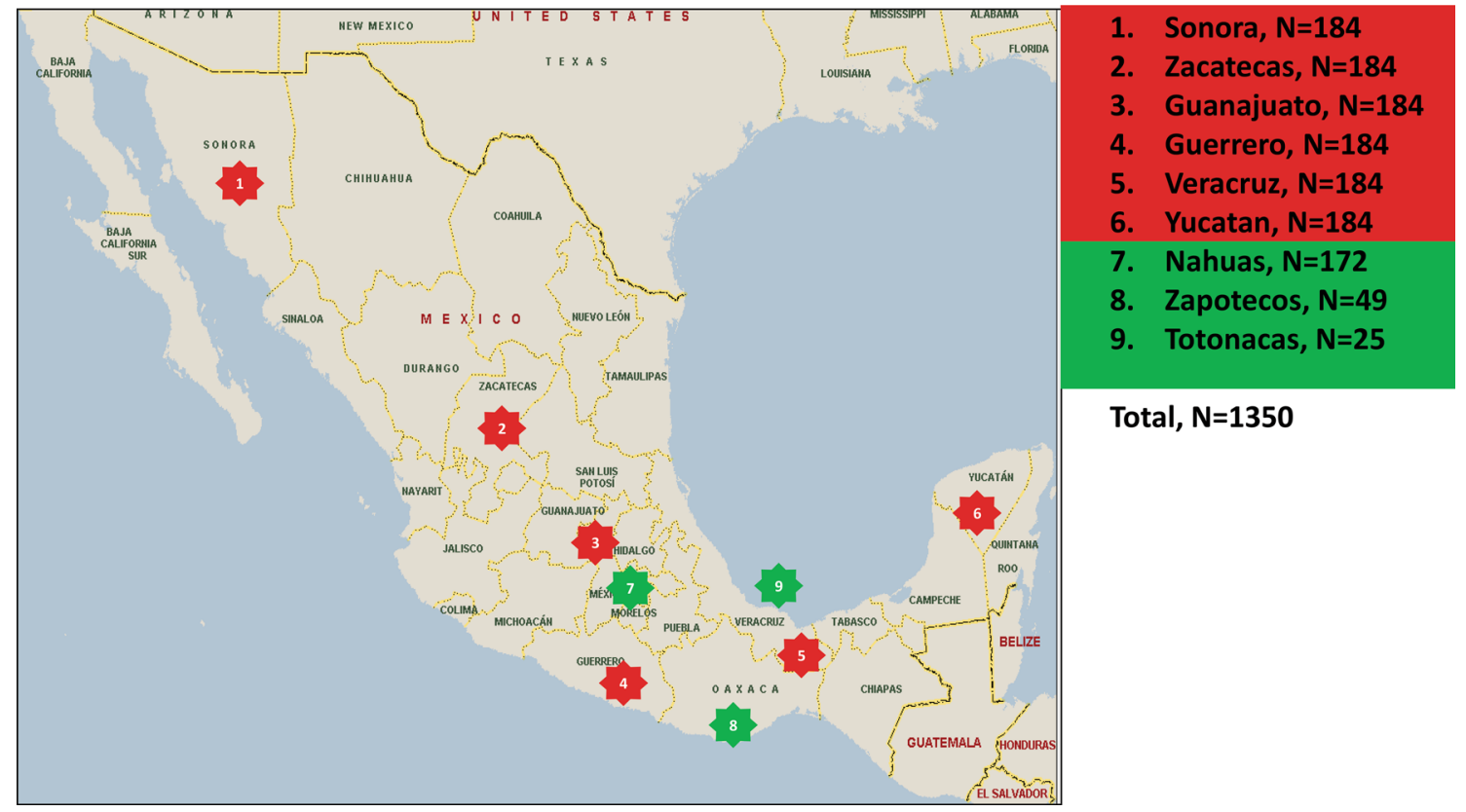

Fig. 2 Geographical distribution of the Mestizos (MEX) and the three Amerindian (AMI) Mexican populations included in the study

Genotype data from public databases

Individual genotype data, publicly available, from East Asian (ASIA), African (AFR) and European (EUR) participants in the 1000 Genomes Project, Phase I were retrieved from www.1000genomes.org. From East Asia, 97 Han Chinese from Beijing, 89 Japanese from Tokyo and 100 Southern Han Chinese were included. The African population consisted of 97 Luhya from Webuye, Kenya and 88 Yoruba from Ibadan, Nigeria. Finally, the European population included 89 British from England and Scotland, 93 Finnish, 98 Toscani from Italy and 85 Utah residents with Northern and Western European ancestry. Detailed information on the projects and the recruited subjects can be found in www.1000genomes.org (Genomes Project et al. 2010). For MTHFR C677T, genotyping data were retrieved in August 2013 from the ALlele FREquency Database http://alfred.med.yale.edu/alfred/index.asp and were used to visualize the world distribution of the risk genotype (Rajeevan et al. 2012).

\section{Statistical analysis}

Allele and genotype frequencies were calculated by direct counting (Griffiths et al. 2000). Deviations from HardyWeinberg equilibrium $(P<0.005)$ and comparison of allele or genotype frequencies between different populations were tested with Fisher's exact test. Calculated confidence intervals $(95 \%)$ around a completion rate were constructed in SPSS. Genotype distributions in different populations were compared using Kruskal-Wallis test. All maps were constructed using the MapPoint software (Microsoft MapPoint, version 2010).

\section{Results}

All SNPs in the Mexican Mestizos (MEX) had call rates $>95 \%$, and in the Amerindians (AMI) samples, three genotyping assays (MTHFDl G1958A, MTHFR A1298C, MTR A2756G) had a call rate of $>97 \%$ and five assays (MTHFR C677T, MTRR A66G, SLC19A1 A80G, TCN2 C77G) had a call rate of $89 \%$ (Supp. Table 1). For all SNPs, genotypic frequencies were in accordance with Hardy-Weinberg Equilibrium $(P>0.005)$. The concordance between our frequency genotyping data obtained by allelic discrimination with TaqMan ${ }^{\circledR}$, and those acquired from the Mexican Genome Diversity Project using Illumina 510 and $550 \mathrm{~K}$ arrays was high $(=99.43 \%)$.

Geographical distribution of folate-mediated onecarbon metabolism pathway alleles and genotypes showing continental differences but not major intrapopulation differences in Mexican Mestizos

Four of the eight variants analyzed, FOLH1 T484C, TCN2 C77G, SLC19A1 A80G and MTR A2756G, showed a similar average frequency distribution between MEX, AMI and EUR groups (MAF frequencies: 23-26, 31-43, 54-58 and $17-25 \%$, respectively), which correlates with either 


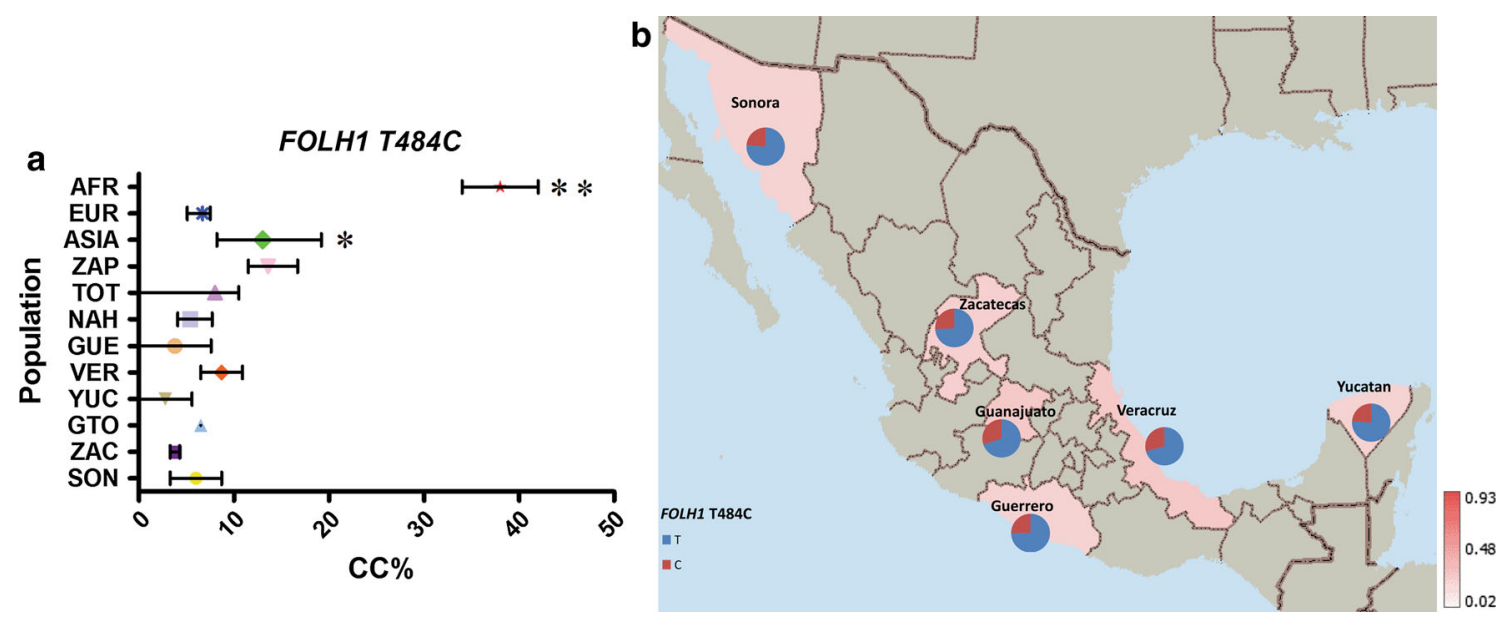

Fig. 3 a Comparative frequency of the homozygotes for the risk allele of FOLH T484C in the studied populations $\left({ }^{*} P\right.$ value $>0.0001$ and $<0.05, * * P$ value $<0.0001$ for significant differences in genotype

frequencies), b minor allele frequency of $F O L H \mathrm{~T} 484 \mathrm{C}$ in six Mexican Mestizo groups a

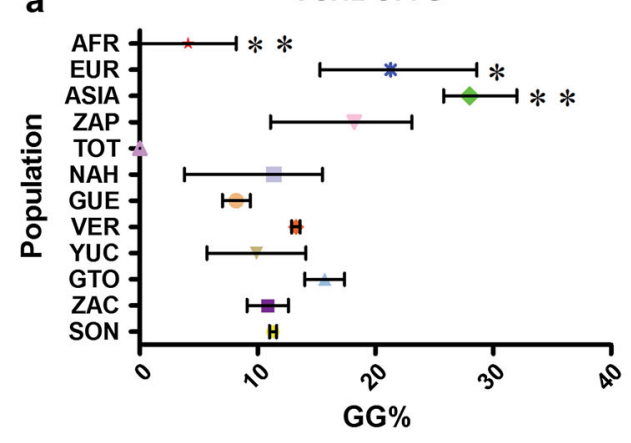

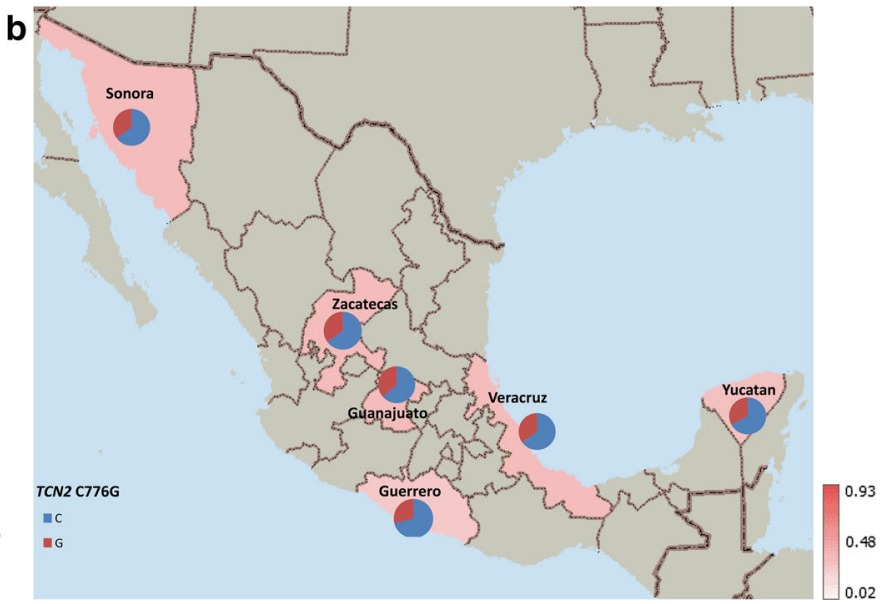

Fig. 4 a Comparative frequency of the risk allele homozygotes for $T C N 2 \mathrm{C} 77 \mathrm{G}$ in the studied populations $(* P$ value $>0.0001$ and $<0.05$, $* * P$ value $<0.0001$ for significant differences in genotype frequencies), b minor allele frequency of TCN2 C77G in six Mexican Mestizo groups

no significant differences or very low variation in their frequency within MEX groups (Figs. 3, 4, 5, 6).

The risk genotype (CC) for FOLH1 T484C had a frequency $\leq 14 \%$ in all Mexican groups (MEX, NAH, ZAP and TOT). EUR and ASIA had a CC frequency of $6 \%$ and of $13 \%$, respectively. The highest CC frequency was observed in the AFR group (34 \%) (Supp. Table 2; Fig. 3).

The risk genotype (GG) for $T C N 2 \mathrm{C} 77 \mathrm{G}$ ranged from 8 to $18 \%$ in all Mexican populations (MEX and AMI), excluding TOT in which the GG genotype was absent. The frequency of the GG genotype was higher in EUR $(20 \%)$ and ASIA (29\%) than in AFR (6\%), where it had the lowest frequency of all continental groups (Supp. Table 3; Fig. 4).

The risk genotype (GG) for SLC19A1 A80G had a high frequency in MEX, AMI and EUR populations, ranging from $25 \%$ in ZAP to $38 \%$ in VER (Supp. Table 4; Fig. 5). ASIA had $21 \%$ of the GG genotype and AFR showed the lowest frequency (9\%) (Supp. Table 4; Fig. 5).

Finally, the risk genotype (GG) for MTR A2756G was $\leq 11 \%$ in most populations included (Supp. Table 5; Fig. 6). EUR populations and MEX populations with high European ancestry, SON and GUE had the lowest frequencies for the MTR A2756G $(\leq 2 \%)$. In ZAP, there was no carrier of the MTR A2756G GG genotype. AFR had the highest frequency of the GG genotype for this SNP $(11 \%)$.

Geographical distribution of folate-mediated onecarbon metabolism pathway alleles and genotypes showing continental variation and intra-population differences in Mexican Mestizos

In contrast to the additional four out of the eight variants analyzed, MTRR A66G, MTHFR C677T, A1298AC and 

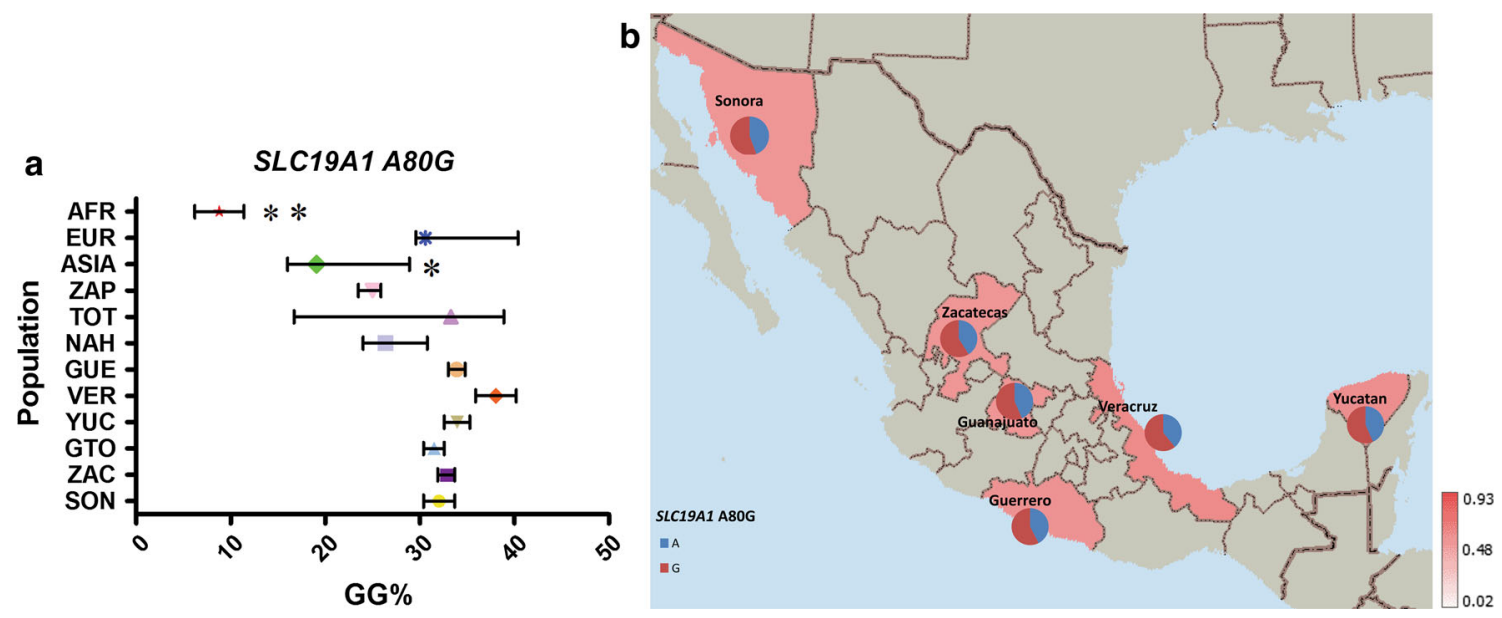

Fig. 5 a Comparative frequency of the risk allele homozygotes for SLC19A1 A80G in the studied populations $\left({ }^{*} P\right.$ value $>0.0001$ and $<0.05, * * P$ value $<0.0001$ for significant differences in genotype

frequencies), b minor allele frequency of $S L C 19 A 1$ A80G in the six Mexican Mestizo Groups

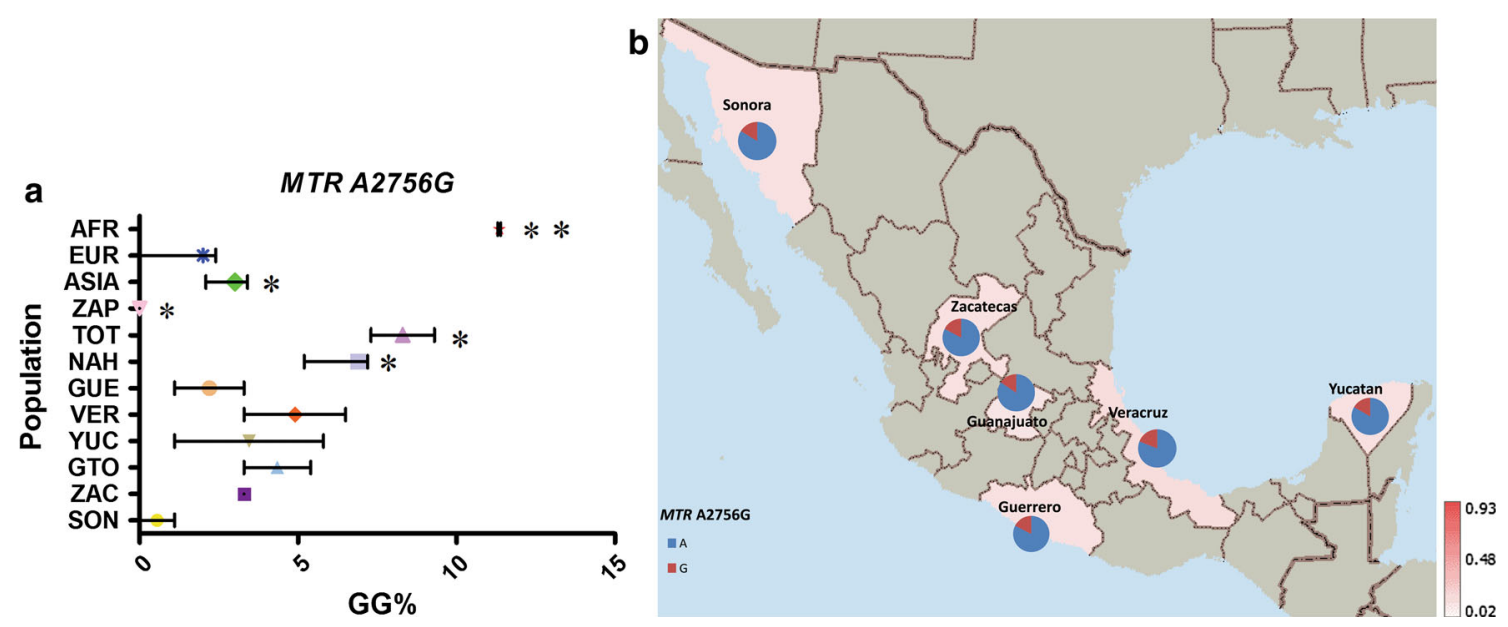

Fig. 6 a Comparative frequency of the risk allele homozygotes for $M T R$ A2756G in the studied populations $(* P$ value $>0.0001$ and $<0.05, * * P$ value $<0.0001$ for significant differences in genotype

MTHFDl G1958A showed a gradient in the frequency between MEX groups and highly significant differences between AMI and EUR groups $\left(P\right.$ values $\left.<10^{-4}\right)$.

The risk genotype (GG) for MTRR A66G presented the highest frequency in EUR (33\%), deviating from ASIA, AFR, AMI and MEX (Supp. Table 6; Fig. 7). Among MEX, the group with the highest European ancestry (SON) had the highest frequency of GG genotype carriers (Fig. 7). In EUR, we observed a North-to-South gradient in the GG genotype frequencies, with Finnish having the highest frequency (44\%), followed by British (32\%) and Italians having the lowest of the three (19\%) (data not shown).

The risk genotype (CC) for the MTHFR A1298C presented a similar distribution as for MTRR A66G. Overall, the frequency of CC genotype was $\leq 11 \%$, and EUR and SON within the MEX groups had the highest frequencies, frequencies), b minor allele frequency of $M T R$ A2756G in six Mexican Mestizo groups

11 and $7 \%$, respectively (Supp. Table 7; Fig. 8). In contrast to MTRR A66G, European populations from the 1,000 GP had similar risk genotypes frequencies for MTHFR A1298C (data not shown).

In MTHFR C677T, homozygotes for the risk $\mathrm{T}$ allele were found in very high frequency in all three AMI groups included in the study. NAH and ZAP had a frequency of subjects with a TT genotype of 59 and $62 \%$, whereas in TOT $36 \%$ had a TT genotype (Supp. Table 8; Fig. 9). In AFR populations, there was no TT genotype, whereas ASIA and EUR had a 15 and $13 \%$, respectively. In the MEX groups, the TT frequency ranged from $17 \%$ in SON to $33 \%$ in GUE. The risk allele had an average frequency of $50 \%$ frequency in MEX (Supp. Table 8; Fig. 9). Genotyping data for MTHFR C677T retrieved from ALFRED database (including studies by Botto et al., Wilcken et al. and Yang et al.) revealed a similar world 


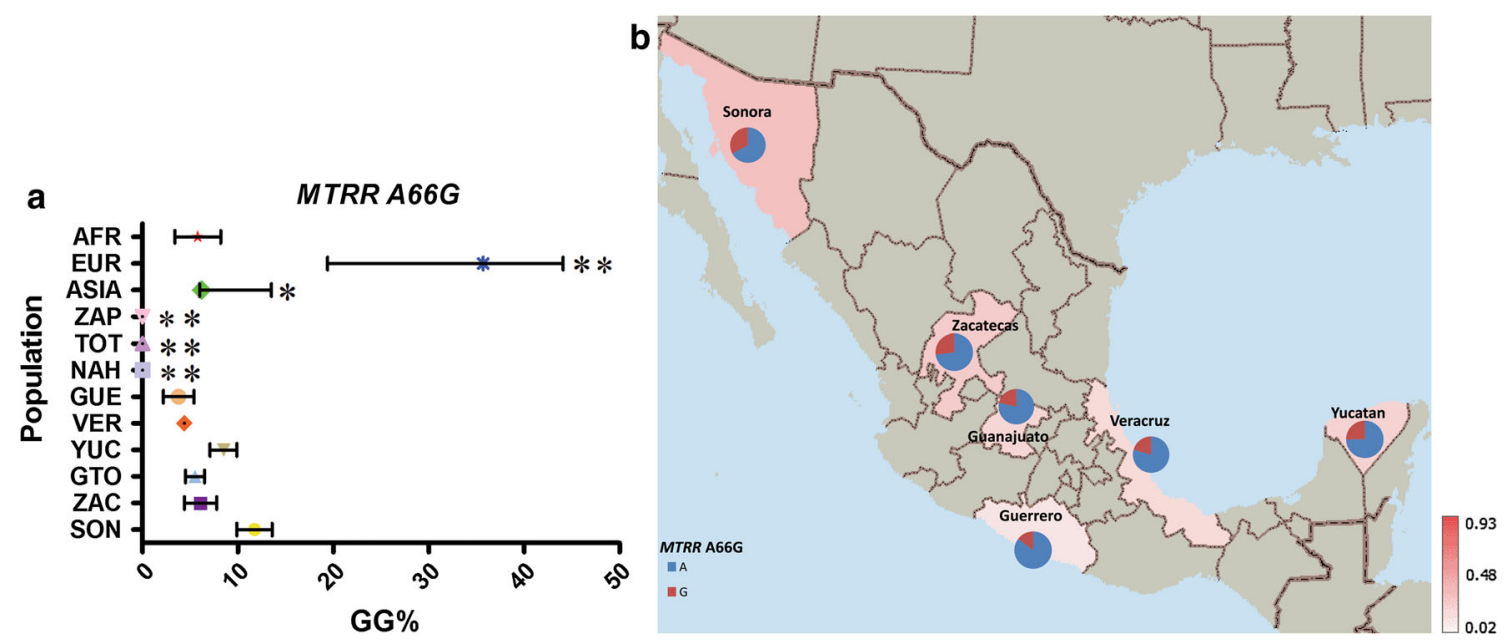

Fig. 7 a Comparative frequency of the risk allele homozygotes for MTRR A66C in the studied populations $(* P$ value $>0.0001$ and $<0.05$, $* * P$ value $<0.0001$ for significant differences in genotype frequencies), $\mathbf{b}$ minor allele frequency of MTRR A66C in six Mexican Mestizo groups

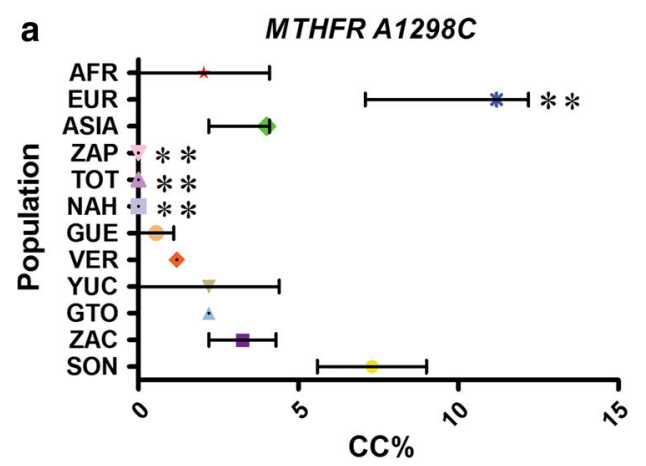

Fig. 8 a Comparative frequency of the risk allele homozygotes for MTHFR A1298C in the studied populations $(* P$ value $>0.0001$ and $<0.05, * * P$ value $<0.0001$ for significant differences in genotype

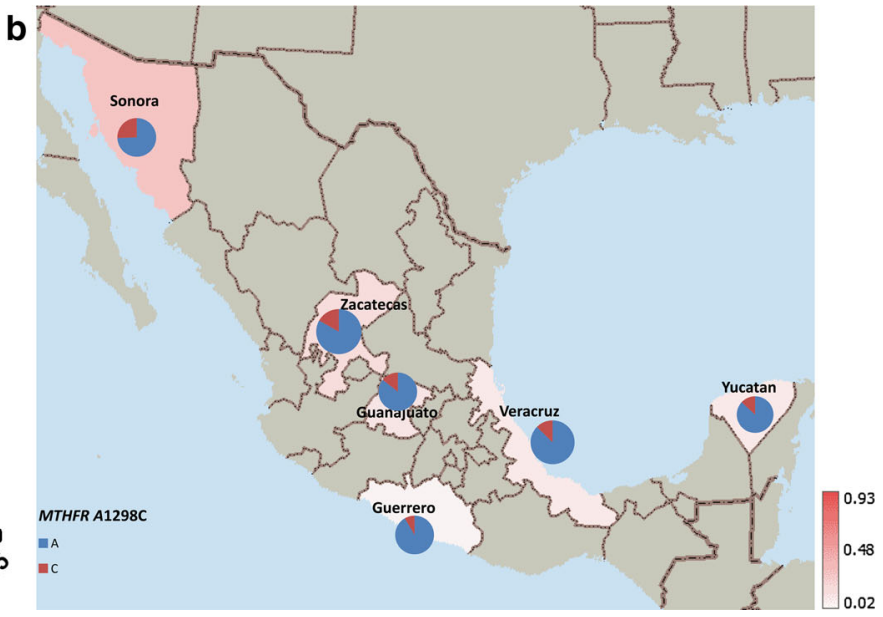

frequencies), b minor allele frequency of MTHFR A1298C in six Mexican Mestizo groups

Gender differences in the genotypes distribution in Mexican Mestizos

We examined whether the genotypes distribution for the eight SNPs were significantly different between males and females in the MEX populations. We only found a significant difference in the genotype distribution between genders for FOLH1 T484C $(P=0.0006)$. In women, MAF of FOLH1 T484C was higher than in men (Suppl. Table 10; Suppl. Fig. 1). For SLC19A1 A80G, MTHFD1 G1958A, MTHFR A1298C and MTR A2756G, borderline significant differences were found (Suppl. Table 1). 

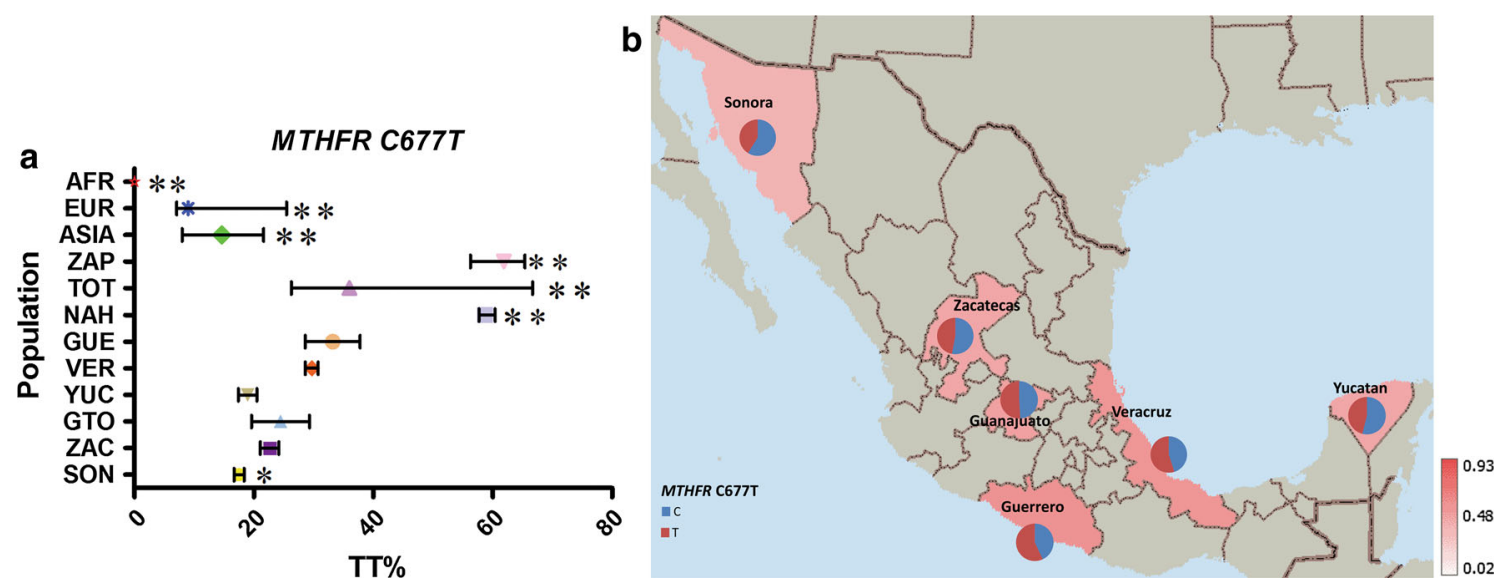

Fig. 9 a Comparative frequency of the risk allele homozygotes for MTHFR C677T in the studied populations (* $P$ value $>0.0001$ and $<0.05, * * P$ value $<0.0001$ for significant differences in genotype

frequencies), b minor allele frequency of MTHFR C677T in six Mexican Mestizo groups
Fig. 10 Global distribution of TT \% for MTHFR C677T (Source: ALFRED database)

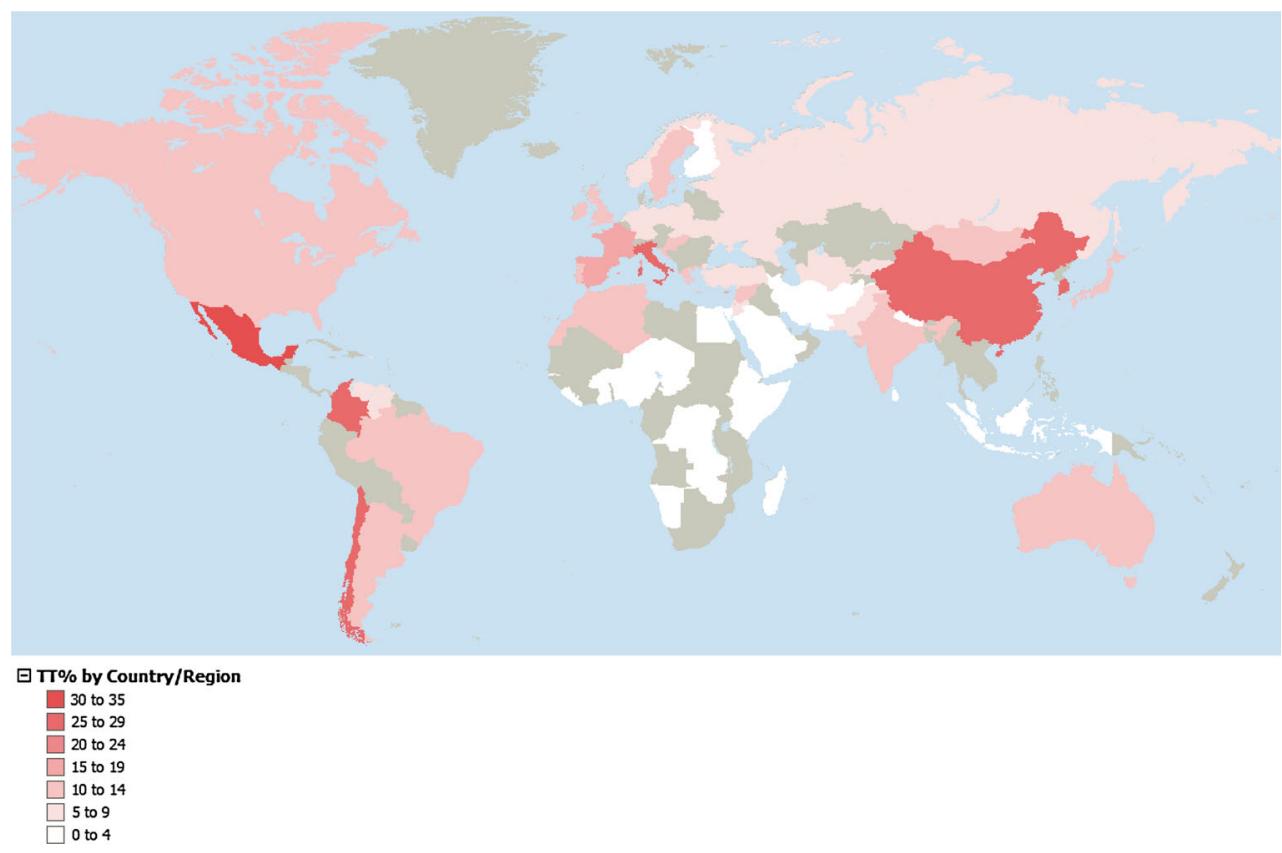

\section{Discussion}

Our study investigated the distribution of eight disease risk-associated alleles and genotypes of functional SNPs within seven genes encoding for enzymes from the folate pathway in both, admixed (MEX) and indigenous (AMI) Mexican populations, and a comparative analysis was done against their frequencies in samples from major continental population groups: European (EUR), East Asian (ASIA) and Africans (AFR).

Some risk genotypes frequencies were very similar among and between MEX and AMI groups, including FOLH1 T484C, TCN2 C77G and MTR A2756G. Of these, TCN2 C77G showed continental differences, and FOLH1
T484C, MTR A2756G and SLC19A1 A80G had similar frequencies in most populations analyzed, only showing a significantly different frequency in AFR groups. In contrast, the risk genotypes for MTRR A66C, MTHFR A1298C, MTHFR C677T and MTHFD1 G1958C variants showed both continental and intra-population differences in MEX and AMI groups $(P<0.0001)$. In the three AMI groups included in our study, no MTRR 66CC or MTHFR $1298 \mathrm{CC}$ genotypes were found, and a low frequency of the risk allele for both was observed (MAF $\leq 7 \%$ ). These risk genotypes were more frequent in EUR (33 and $11 \%$, respectively), and among the MEX groups had the highest frequency in SON, in relation to the high European ancestral contribution to this population group. The risk- 


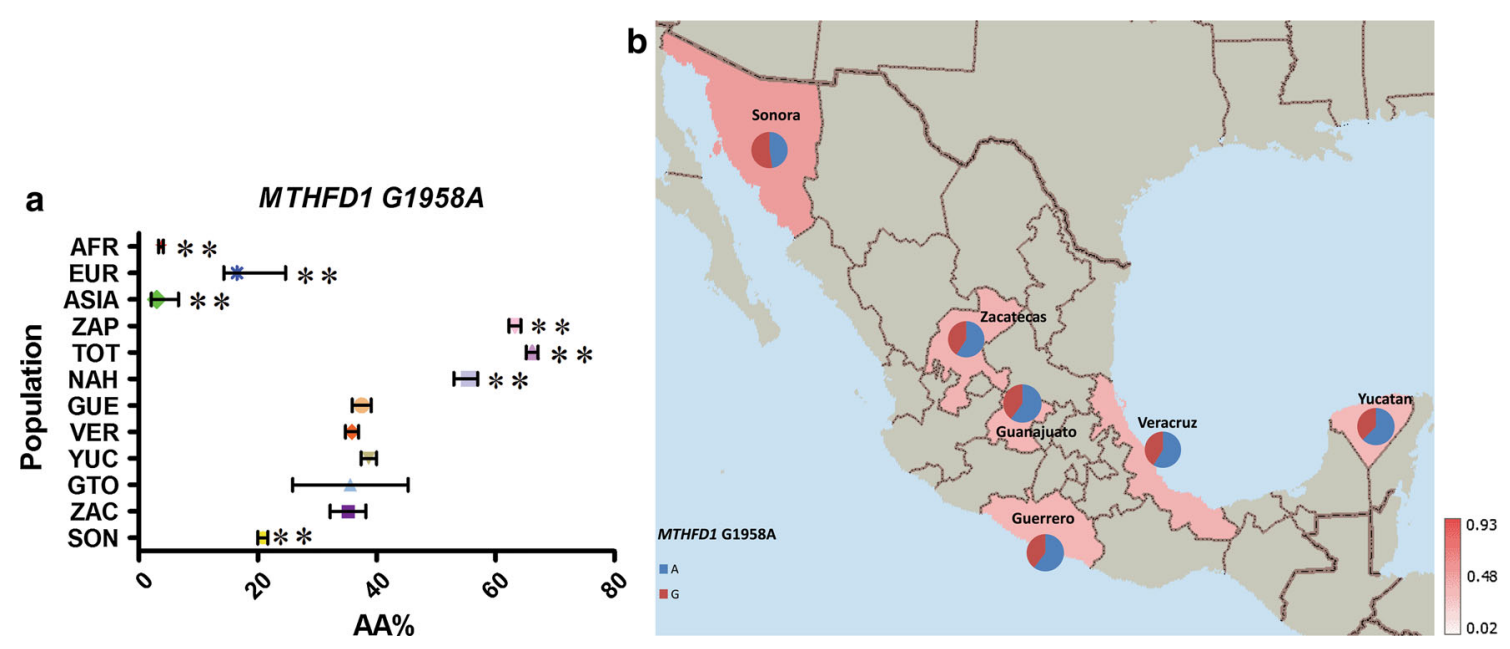

Fig. 11 a Comparative frequency of the risk allele homozygotes for $M T H F D 1$ G1958A in the studied populations $(* P$ value $>0.0001$ and $<0.05$, **P value $<0.0001$ for significant differences in genotype

associated genotypes MTHFD1 1958AA and MTHFR 677TT had a particularly high frequency in the MEX population, 34 and $25 \%$, respectively. The frequencies of both SNPs in the AMI groups included in our study were $>55 \%$, supporting the hypothesis that this phenomenon is related to the Amerindian ancestral contribution to the admixture process (Wilcken et al. 2003; Davalos et al. 2000; Juarez-Velazquez et al. 2010). This is further supported by the observed gradient in the frequency of these variants in the MEX populations analyzed, within which, the highest and the lowest frequencies were observed in GUE and SON, the groups with, respectively, the highest and the lowest Amerindian ancestry contribution in this set of samples (Silva-Zolezzi et al. 2009). Interestingly, for these SNPs, the frequencies of the risk-associated genotype were lower in ASIA and EUR populations $(<20 \%)$ and almost absent in the AFR populations $(\leq 4 \%)$, which underlines the more specific relevance of these genetic variants for populations with Amerindian ancestry, such as most populations of central and south America, Native American and most Hispanic groups living in the USA.

Our observed MTHFR C677T frequencies were similar to those of populations with the same ancestry of the 1000GP or of previous reports (Davalos et al. 2000; JuarezVelazquez et al. 2010; Wilcken et al. 2003). Nevertheless, we have provided a more detailed description of within population differences that was not captured in any of the previous studies. Our results are in agreement with a previous study investigating the prevalence of MTHFR 677TT genotype in different regions in Mexico in which the lowest frequency was observed in the north of the country (in our study SON) and the highest frequency in the center of the country (in our study GUE) (Mutchinick et al. 1999). frequencies), b minor allele frequency of MTHFD1 G1958A in six Mexican Mestizo groups

In the same study, Mutchinick et al. reported highly significant differences of MTHFR 677TT genotype frequency in Mexico compared with other countries, supporting that the high prevalence of NTDs in Mexico may be related to the particularly frequent presence of the non-functional $\mathrm{T}$ allele in the population. Indeed, in Mexico, the highest prevalence of NTDs in the world has been documented. According to the data from the program of Registry and Epidemiological Surveillance of External Congenital Malformations (RYVEMCE), approximately one in 250 conceptions that reach 20 weeks of gestation or more present a NTD. This number is three or four times higher than that observed in populations from South America and Spain (Mutchinick et al. 1988, 1999; Conjoined twins-an epidemiological study based on 312 cases. The International Clearinghouse for Birth Defects Monitoring Systems 1991). The prevalence at birth for anencephaly and spina bifida, the NTDs most frequently observed, was 18.4 and 15.6 per 10,000 births, respectively (Mutchinick et al. 1988, 1999). Interestingly, the state of Guerrero (GUE) has shown a trend of significantly increased annual NTD mortality rate per 10,000 living born infants since 1990 (Ramirez-Espitia et al. 2003).

The investigation of MTHFR 677TT in NTDs risk has been well documented with studies showing a significant association of the genotype with NTDs risk (Yan et al. 2012; Harisha et al. 2010; Grandone et al. 2006) and others not supporting the association or revealing a complex mechanism by which folate intake, parental and infant genotype interplay (Johnson et al. 1999; Shaw et al. 1998; Shields et al. 1999).

In this analysis, we observed that the 1000GP Han Chinese population data MTHFR 677TT had a lower 
frequency $(15 \%)$ compared with a large study recently published and being included also in ALFRED, which included $>15,000$ adults of Han nationality from 10 regions in China (Yang et al. 2013). Older reports on the MTHFR 677TT have also reported lower frequencies compared with Yang et al. (Wilcken et al. 2003). This may suggest that important differences in the frequency distribution of functional variants within populations can be more accurately described when more comprehensive analyses are done. Considering the relevance of the MTHFR C677T polymorphism for public health, these results highlight the potential need of more detailed studies in different populations to better understand the worldwide frequency distribution of this and also other clinically relevant variants.

Though a previous study has reported a decreased proportion of MTHFR 677TT in female newborns (Rozen et al. 1999), proposing that gender effects exist, our study has not identified a large gender effect for any of the studied variants, in accordance with the previous study in the Han Chinese (Yang et al. 2013).

Our study provides evidence that functional variants other than the MTHFR C677T and relevant to the folatemediated one-carbon metabolism are also specifically enriched in populations, and this can be relevant for informing public health policy but also supporting or generating hypotheses related to their potential role in selection processes. For example, the less studied FOLHI $\mathrm{T} 484 \mathrm{C}$ and TCN2 $\mathrm{C} 77 \mathrm{G}$ risk variants were found more abundant in AFR and ASIA populations, respectively (Gueant et al. 2007), than in the rest of the populations included in our study. Interestingly, both proteins are involved in the intestinal absorption of factors (folate and $\mathrm{B}_{12}$ ) with a pivotal role in the homocysteine metabolic pathway and the functional variants are thought to impair their function (Gueant et al. 2007; Guo et al. 2013). There are direct associations of these SNPs with NTDs (Guo et al. 2013; Gueant-Rodriguez et al. 2003; Martinelli et al. 2006) and autism (Martinelli et al. 2006). Plausible hypotheses explaining their population distribution could be that they may be part of the selective pressure process or providing a survival advantage. As an example, in $\mathrm{CC}$ individuals for the TCN2 C77G allele, tHcy levels seem to be more responsive to dietary $\mathrm{B}_{12}$ or $\mathrm{B}_{12}$ supplementation (Garrod et al. 2010); it has been also proposed that this polymorphism could influence the susceptibility to malaria, as higher frequencies of the risk variant were observed in patients with severe malaria (Gueant et al. 2007). FOLHI T484C in our study presents almost an exclusively high frequency in populations with an African ancestry; the polymorphism has been associated with plasma folate levels suggesting that genetic frequencies may be under population-specific evolutionary mechanisms related to folate bioavailability (DeVos et al. 2008).
MTHFR C677T has also been proposed to interact with environmental factors to confer selective pressure; for example, a correlation with ultraviolet radiation exposure has been proposed, which is thought to partly explain the North-to-South gradient of this risk variant gradient in Europe (Yafei et al. 2012; Cordain and Hickey 2006). A similar phenomenon may be related to the inverse gradient observed for MTRR A66C for which higher frequencies of MTRR 66C are found in northern Europe (44\% in Finland) compared with southern Europe (19\% in Italy). In the case of the MTHFR polymorphisms, several relevant genenutrient interactions have been described, for example, MTHFR 677T was proposed to confer a selective advantage to populations with higher folate intake, such as south Europeans and Mexicans (Gueant-Rodriguez et al. 2006), and more recently, it was found to be associated with a decrease of both serum folate and cell folate concentrations and an altered mix of circulating folate forms (Farrell et al. 2013). A nutrigenetic association has been reported with vitamin $\mathrm{B}_{2}$, a precursor of the flavino-adenine dinucleotide (FAD) and a known cofactor of the MTHFR enzyme. In this case, carriers of the TT genotype with suboptimal dietary levels of vitamin $B_{2}$ are benefited by the increased intake of the vitamin improving substantially their tHcy levels and blood pressure (Horigan et al. 2010; McNulty et al. 2006; Wilson et al. 2012, 2013). An improved blood pressure control for MTHFR 677TT genotype carriers without being influenced by the type of antihypertensive medication has been demonstrated in pre-hypertensive and hypertensive individuals following $\mathrm{B}_{2}$ supplementation (Wilson et al. 2012). In Mexico, high rates of increased blood pressure have been recently documented with $\sim 32 \%$ of the population over 50 years of age having at least stage I systolic hypertension and $>47 \%$ being at prehypertensive levels (Cortes-Hernandez et al. 2014). Less than $50 \%$ of the populations in Mexico that are aware of their increased blood pressure are estimated to control their blood pressure through either medication or lifestyle interventions (Prince et al. 2012; Basu and Millett 2013). The described interactions between MTHFR C677T, dietrelated factors such as vitamin $\mathrm{B}_{2}$ and control of blood pressure should be considered at least during dietary recommendations, particularly in populations like the Mexican with a high frequency of this risk variant.

In addition to folate and other B vitamins, other dietary factors need to be considered when evaluating the role of the functional variants in the homocysteine metabolic pathway. For example, choline status parameters are influenced by the functional variant MTHFD1 G1958A, when folate status is low (Ivanov et al. 2009). Carriers of the risk variant were found to be in high risk of developing choline deficiency on a low choline diet compared with carriers of the wild-type variant, having thus an increased 
choline intake requirement (Kohlmeier et al. 2005). This is particularly important for specific population groups, such as pregnant women due to the proposed role of choline in fetal brain development (Zeisel 2011). Mexican populations in our study have a highly enriched MTHFD1 1958AA frequency $(\sim 35 \%)$ due to their Amerindian ancestry, as shown in the Nahuas, Totonacas and Zapotecos in our study presenting a MTHFD1 1958AA frequency of $\sim 60 \%$. The need for choline dietary recommendations is therefore more pronounced in these populations.

Finally, studying allelic variants in genes involved in folate metabolism are useful and relevant not only for the nutrigenetics field but also for pharmacogenetics. MTHFR $677 \mathrm{~T}$ may be used to help identify patients with an increased likelihood of methotrexate-related adverse events (Urano et al. 2002; Evans 2002); SLC19A1 A80G has been associated with decreased methotrexate therapeutic response in individuals with rheumatoid arthritis (Dervieux et al. 2004a).

In summary, our study has provided a comparative analysis of functional variants on key enzymes in the folate and homocysteine metabolic pathway in an admixed population consisting of 1,350 Mexican males and females. By including three Amerindian groups and publicly available data from European, African and East Asian populations, we could provide explanation for the differential distribution of the risk genotypes in Mexico and show their worldwide frequency overview. Our results showed that highly frequent risk variants have population-specific distributions, potentially resulting from either selective pressure or genetic drift. Incorporating these results together with other worldwide reports on folate pathway-related SNPs and dietary exposures could contribute in understanding the progression and prevalence of relevant disorders. Finally, the potential role of some of these variants in conferring genetic risk to public health relevant disorders and traits warrants that these results are considered for public health policy making and to strengthen preventive strategies to improve the definition of specific dietary requirements in relevant populations.

Open Access This article is distributed under the terms of the Creative Commons Attribution License which permits any use, distribution, and reproduction in any medium, provided the original author(s) and the source are credited.

\section{References}

Basu S, Millett C (2013) Social epidemiology of hypertension in middle-income countries: determinants of prevalence, diagnosis, treatment, and control in the WHO SAGE study. Hypertension 62(1):18-26. doi:10.1161/HYPERTENSIONAHA.113.01374
Berry RJ, Li Z, Erickson JD, Li S, Moore CA, Wang H, Mulinare J, Zhao P, Wong LY, Gindler J, Hong SX, Correa A (1999) Prevention of neural-tube defects with folic acid in China. China-U.S. Collaborative Project for Neural Tube Defect Prevention. N Engl J Med 341(20):1485-1490. doi:10.1056/ NEJM199911113412001

Bonaa KH, Njolstad I, Ueland PM, Schirmer H, Tverdal A, Steigen T, Wang H, Nordrehaug JE, Arnesen E, Rasmussen K, Investigators NT (2006) Homocysteine lowering and cardiovascular events after acute myocardial infarction. $\mathrm{N}$ Engl $\mathrm{J}$ Med 354(15):1578-1588. doi:10.1056/NEJMoa055227

Botto LD, Yang Q (2000) 5,10-Methylenetetrahydrofolate reductase gene variants and congenital anomalies: a HuGE review. Am J Epidemiol 151(9):862-877

Carr DF, Whiteley G, Alfirevic A, Pirmohamed M, Fol Ast (2009) Investigation of inter-individual variability of the one-carbon folate pathway: a bioinformatic and genetic review. Pharmacogenomics J 9(5):291-305. doi:10.1038/tpj.2009.29

Conjoined twins-an epidemiological study based on 312 cases. The international clearinghouse for birth defects monitoring systems (1991). Acta geneticae medicae et gemellologiae 40 (34):325-335

Contreras AV, Zenteno JC, Fernandez-Lopez JC, Rodriguez-Corona U, Falfan-Valencia R, Sebastian L, Morales F, Ochoa-Contreras D, Carnevale A, Silva-Zolezzi I (2014) CFH haplotypes and ARMS2, C2, C3, and CFB alleles show association with susceptibility to age-related macular degeneration in Mexicans. Mol Vis 20:105-116

Cordain L, Hickey MS (2006) Ultraviolet radiation represents an evolutionary selective pressure for the south-to-north gradient of the MTHFR 677TT genotype. Am J Clin Nutr 84 (5):1243; author reply 1244-1245

Cortes-Hernandez DE, Lundelin KJ, Picazzo-Palencia E, de la Cruz JJ, Sanchez JJ, Banegas JR (2014) The burden of blood-pressurerelated cardiovascular mortality in Mexico. Int $\mathrm{J}$ Hypertens 2014:427684. doi: 10.1155/2014/427684

Davalos IP, Olivares N, Castillo MT, Cantu JM, Ibarra B, Sandoval L, Moran MC, Gallegos MP, Chakraborty R, Rivas F (2000) The C677T polymorphism of the methylenetetrahydrofolate reductase gene in Mexican mestizo neural-tube defect parents, control mestizo and native populations. Ann Genet 43(2):89-92

Dervieux T, Furst D, Lein DO, Capps R, Smith K, Walsh M, Kremer J (2004a) Polyglutamation of methotrexate with common polymorphisms in reduced folate carrier, aminoimidazole carboxamide ribonucleotide transformylase, and thymidylate synthase are associated with methotrexate effects in rheumatoid arthritis. Arthritis Rheum 50(9):2766-2774. doi:10.1002/art.20460

Dervieux T, Kremer J, Lein DO, Capps R, Barham R, Meyer G, Smith K, Caldwell J, Furst DE (2004b) Contribution of common polymorphisms in reduced folate carrier and gamma-glutamylhydrolase to methotrexate polyglutamate levels in patients with rheumatoid arthritis. Pharmacogenetics 14(11):733-739

DeVos L, Chanson A, Liu Z, Ciappio ED, Parnell LD, Mason JB, Tucker KL, Crott JW (2008) Associations between single nucleotide polymorphisms in folate uptake and metabolizing genes with blood folate, homocysteine, and DNA uracil concentrations. Am J Clin Nutr 88(4):1149-1158

Ding W, Zhou DL, Jiang X, Lu LS (2013) Methionine synthase A2756G polymorphism and risk of colorectal adenoma and cancer: evidence based on 27 studies. PLoS ONE 8(4):e60508. doi:10.1371/journal.pone. 0060508

Evans WE (2002) Differing effects of methylenetetrahydrofolate reductase single nucleotide polymorphisms on methotrexate efficacy and toxicity in rheumatoid arthritis. Pharmacogenetics 12(3):181-182 
Farrell CJ, Kirsch SH, Herrmann M (2013) Red cell or serum folate: what to do in clinical practice? Clin Chem Lab Med 51(3):555-569. doi:10.1515/cclm-2012-0639

Forges T, Monnier-Barbarino P, Alberto JM, Gueant-Rodriguez RM, Daval JL, Gueant JL (2007) Impact of folate and homocysteine metabolism on human reproductive health. Hum Reprod Update 13(3):225-238. doi:10.1093/humupd/dml063

Fredriksen A, Meyer K, Ueland PM, Vollset SE, Grotmol T, Schneede J (2007) Large-scale population-based metabolic phenotyping of thirteen genetic polymorphisms related to onecarbon metabolism. Hum Mutat 28(9):856-865. doi:10.1002/ humu.20522

Frosst P, Blom HJ, Milos R, Goyette P, Sheppard CA, Matthews RG, Boers GJ, den Heijer M, Kluijtmans LA, van den Heuvel LP et al (1995) A candidate genetic risk factor for vascular disease: a common mutation in methylenetetrahydrofolate reductase. Nat Genet 10(1):111-113. doi:10.1038/ng0595-111

Garrod MG, Allen LH, Haan MN, Green R, Miller JW (2010) Transcobalamin $\mathrm{C} 776 \mathrm{G}$ genotype modifies the association between vitamin B12 and homocysteine in older Hispanics. Eur J Clin Nutr 64(5):503-509. doi:10.1038/ejcn.2010.20

Gaughan DJ, Kluijtmans LA, Barbaux S, McMaster D, Young IS, Yarnell JW, Evans A, Whitehead AS (2001) The methionine synthase reductase (MTRR) A66G polymorphism is a novel genetic determinant of plasma homocysteine concentrations. Atherosclerosis 157(2):451-456

Genomes Project C, Abecasis GR, Altshuler D, Auton A, Brooks LD, Durbin RM, Gibbs RA, Hurles ME, McVean GA (2010) A map of human genome variation from population-scale sequencing. Nature 467(7319):1061-1073. doi:10.1038/nature09534

Grandone E, Corrao AM, Colaizzo D, Vecchione G, Di Girgenti C, Paladini D, Sardella L, Pellegrino M, Zelante L, Martinelli P, Margaglione M (2006) Homocysteine metabolism in families from southern Italy with neural tube defects: role of genetic and nutritional determinants. Prenat Diagn 26(1):1-5. doi:10.1002/ pd. 1359

Greene ND, Stanier P, Copp AJ (2009) Genetics of human neural tube defects. Hum Mol Genet 18(R2):R113-R129. doi:10.1093/hmg/ ddp 347

Griffiths AJF, Miller J, Suzuki DT, Lewontin RC, Gelbart WM (2000) An introduction to genetic analysis. W. H. Freeman, New York

Gueant JL, Chabi NW, Gueant-Rodriguez RM, Mutchinick OM, Debard R, Payet C, Lu X, Villaume C, Bronowicki JP, Quadros EV, Sanni A, Amouzou E, Xia B, Chen M, Anello G, Bosco P, Romano C, Arrieta HR, Sanchez BE, Romano A, Herbeth B, Anwar W, Namour F (2007) Environmental influence on the worldwide prevalence of a $776 \mathrm{C}->\mathrm{G}$ variant in the transcobalamin gene (TCN2). J Med Genet 44(6):363-367. doi:10.1136/ jmg.2006.048041

Gueant-Rodriguez RM, Rendeli C, Namour B, Venuti L, Romano A, Anello G, Bosco P, Debard R, Gerard P, Viola M, Salvaggio E, Gueant JL (2003) Transcobalamin and methionine synthase reductase mutated polymorphisms aggravate the risk of neural tube defects in humans. Neurosci Lett 344(3):189-192

Gueant-Rodriguez RM, Gueant JL, Debard R, Thirion S, Hong LX, Bronowicki JP, Namour F, Chabi NW, Sanni A, Anello G, Bosco P, Romano C, Amouzou E, Arrieta HR, Sanchez BE, Romano A, Herbeth B, Guilland JC, Mutchinick OM (2006) Prevalence of methylenetetrahydrofolate reductase $677 \mathrm{~T}$ and $1298 \mathrm{C}$ alleles and folate status: a comparative study in Mexican, West African, and European populations. Am J Clin Nutr 83(3):701-707

Guo J, Xie H, Wang J, Zhao H, Wang F, Liu C, Wang L, Lu X, Bao Y, Zou J, Wang G, Niu B, Zhang T (2013) The maternal folate hydrolase gene polymorphism is associated with neural tube defects in a high-risk Chinese population. Genes Nutr 8(2):191-197. doi:10.1007/s12263-012-0309-3
Harisha PN, Devi BI, Christopher R, Kruthika-Vinod TP (2010) Impact of 5,10-methylenetetrahydrofolate reductase gene polymorphism on neural tube defects. J Neurosurg Pediatr 6(4):364-367. doi:10.3171/2010.8.PEDS1072

Homocysteine Studies C (2002) Homocysteine and risk of ischemic heart disease and stroke: a meta-analysis. JAMA 288(16):2015-2022

Horigan G, McNulty H, Ward M, Strain JJ, Purvis J, Scott JM (2010) Riboflavin lowers blood pressure in cardiovascular disease patients homozygous for the $677 \mathrm{C}->\mathrm{T}$ polymorphism in MTHFR. J Hypertens 28(3):478-486. doi:10.1097/HJH.0b013 e328334c126

Ivanov A, Nash-Barboza S, Hinkis S, Caudill MA (2009) Genetic variants in phosphatidylethanolamine $\mathrm{N}$-methyltransferase and methylenetetrahydrofolate dehydrogenase influence biomarkers of choline metabolism when folate intake is restricted. J Am Diet Assoc 109(2):313-318. doi:10.1016/j.jada.2008.10.046

Jennings BA, Willis G (2014) How folate metabolism affects colorectal cancer development and treatment; a story of heterogeneity and pleiotropy. Cancer Lett. doi:10.1016/j.canlet.2014. 02.024

Johnson WG, Stenroos ES, Heath SC, Chen Y, Carroll R, McKoy VV, Chatkupt S, Lehner T (1999) Distribution of alleles of the methylenetetrahydrofolate reductase (MTHFR) C677T gene polymorphism in familial spina bifida. Am $\mathrm{J}$ Med Genet 87(5):407-412

Juarez-Velazquez R, Canto P, Canto-Cetina T, Rangel-Villalobos H, Rosas-Vargas H, Rodriguez M, Canizales-Quinteros S, Velazquez Wong AC, Ordonez-Razo RM, Vilchis-Dorantes G, CoralVazquez RM (2010) Analysis of polymorphisms in genes (AGT, MTHFR, GPIIIa, and GSTP1) associated with hypertension, thrombophilia and oxidative stress in Mestizo and Amerindian populations of Mexico. Dis Markers 28(5):323-331. doi:10. 3233/DMA-2010-0712

Kohlmeier M, da Costa KA, Fischer LM, Zeisel SH (2005) Genetic variation of folate-mediated one-carbon transfer pathway predicts susceptibility to choline deficiency in humans. Proc Natl Acad Sci U S A 102(44):16025-16030. doi:10.1073/pnas.05042 85102

Koushik A, Kraft P, Fuchs CS, Hankinson SE, Willett WC, Giovannucci EL, Hunter DJ (2006) Nonsynonymous polymorphisms in genes in the one-carbon metabolism pathway and associations with colorectal cancer. Cancer Epidemiol Biomarkers Prev 15(12):2408-2417. doi:10.1158/1055-9965.EPI-060624

Laverdiere C, Chiasson S, Costea I, Moghrabi A, Krajinovic M (2002) Polymorphism G80A in the reduced folate carrier gene and its relationship to methotrexate plasma levels and outcome of childhood acute lymphoblastic leukemia. Blood 100(10): 3832-3834. doi:10.1182/blood.V100.10.3832

Leon-Mimila P, Villamil-Ramirez H, Villalobos-Comparan M, Villarreal-Molina T, Romero-Hidalgo S, Lopez-Contreras B, Gutierrez-Vidal R, Vega-Badillo J, Jacobo-Albavera L, PosadasRomeros C, Canizalez-Roman A, Rio-Navarro BD, CamposPerez F, Acuna-Alonzo V, Aguilar-Salinas C, Canizales-Quinteros S (2013) Contribution of common genetic variants to obesity and obesity-related traits in Mexican children and adults. PLoS ONE 8(8):e70640. doi:10.1371/journal.pone.0070640

Lissowska J, Gaudet MM, Brinton LA, Chanock SJ, Peplonska B, Welch R, Zatonski W, Szeszenia-Dabrowska N, Park S, Sherman M, Garcia-Closas M (2007) Genetic polymorphisms in the one-carbon metabolism pathway and breast cancer risk: a population-based case-control study and meta-analyses. Int $\mathrm{J}$ Cancer 120(12):2696-2703. doi:10.1002/ijc.22604

Lonn E, Yusuf S, Arnold MJ, Sheridan P, Pogue J, Micks M, McQueen MJ, Probstfield J, Fodor G, Held C, Genest J Jr, Heart Outcomes Prevention Evaluation I (2006) Homocysteine 
lowering with folic acid and $\mathrm{B}$ vitamins in vascular disease. N Engl J Med 354(15):1567-1577. doi:10.1056/NEJMoa060900 Martinelli M, Scapoli L, Palmieri A, Pezzetti F, Baciliero U, Padula E, Carinci P, Morselli PG, Carinci F (2006) Study of four genes belonging to the folate pathway: transcobalamin 2 is involved in the onset of non-syndromic cleft lip with or without cleft palate. Hum Mutat 27(3):294. doi:10.1002/humu.9411

McNulty H, le Dowey RC, Strain JJ, Dunne A, Ward M, Molloy AM, McAnena LB, Hughes JP, Hannon-Fletcher M, Scott JM (2006) Riboflavin lowers homocysteine in individuals homozygous for the MTHFR 677C- $>$ T polymorphism. Circulation 113(1): $74-80$

Moreno-Estrada A, Gignoux CR, Fernandez-Lopez JC, Zakharia F, Sikora M, Contreras AV, Acuna-Alonzo V, Sandoval K, Eng C, Romero-Hidalgo S, Ortiz-Tello P, Robles V, Kenny EE, NunoArana I, Barquera-Lozano R, Macin-Perez G, Granados-Arriola J, Huntsman S, Galanter JM, Via M, Ford JG, Chapela R, Rodriguez-Cintron W, Rodriguez-Santana JR, Romieu I, SienraMonge JJ, del Rio Navarro B, London SJ, Ruiz-Linares A, Garcia-Herrera R, Estrada K, Hidalgo-Miranda A, JimenezSanchez G, Carnevale A, Soberon X, Canizales-Quinteros S, Rangel-Villalobos H, Silva-Zolezzi I, Burchard EG, Bustamante CD (2014) Human genetics. The genetics of Mexico recapitulates Native American substructure and affects biomedical traits. Science 344 (6189):1280-1285. doi:10.1126/science.1251688

Moskau S, Farmand S, Semmler A, Wullner U, Pohl C, Klockgether T, Linnebank M (2007) The methionine synthase polymorphism c.2756A $>$ G (D919G) influences diastolic blood pressure. J Hum Hypertens 21(5):418-420. doi:10.1038/sj.jhh.1002165

Mutchinick O, Lisker R, Babinski V (1988) The Mexican program of registration and epidemiologic surveillance of external congenital malformations. Salud Publica Mex 30(1):88-100

Mutchinick OM, Lopez MA, Luna L, Waxman J, Babinsky VE (1999) High prevalence of the thermolabile methylenetetrahydrofolate reductase variant in Mexico: a country with a very high prevalence of neural tube defects. Mol Genet Metab 68(4): 461-467. doi:10.1006/mgme.1999.2939

Parveen F, Tuteja M, Agrawal S (2013) Polymorphisms in MTHFR, MTHFD, and PAI-1 and recurrent miscarriage among North Indian women. Arch Gynecol Obstet 288(5):1171-1177. doi:10. 1007/s00404-013-2877-x

Prevention of neural tube defects: results of the Medical Research Council Vitamin Study. MRC Vitamin Study Research Group (1991). Lancet 338 (8760):131-137

Prince MJ, Ebrahim S, Acosta D, Ferri CP, Guerra M, Huang Y, Jacob KS, Jimenez-Velazquez IZ, Rodriguez JL, Salas A, Sosa AL, Williams JD, Gonzalez-Viruet M, Jotheeswaran AT, Liu Z (2012) Hypertension prevalence, awareness, treatment and control among older people in Latin America, India and China: a 10/66 cross-sectional population-based survey. J Hypertens 30(1):177-187. doi:10.1097/HJH.0b013e32834d9eda

Rajeevan H, Soundararajan U, Kidd JR, Pakstis AJ, Kidd KK (2012) ALFRED: an allele frequency resource for research and teaching. Nucleic Acids Res 40 (Database issue):D1010-1015. doi:10.1093/nar/gkr924

Ramirez-Espitia JA, Benavides FG, Lacasana-Navarro M, Martinez JM, Garcia AM, Benach J (2003) Mortality from neural tube defects in Mexico, 1980-1997. Salud Publica Mex 45(5): 356-364

Rosenthal J, Casas J, Taren D, Alverson CJ, Flores A, Frias J (2013) Neural tube defects in Latin America and the impact of fortification: a literature review. Public Health Nutr pp 1-14. doi:10.1017/S1368980013000256

Sharp L, Little J (2004) Polymorphisms in genes involved in folate metabolism and colorectal neoplasia: a HuGE review. Am J Epidemiol 159(5):423-443
Shaw GM, Rozen R, Finnell RH, Wasserman CR, Lammer EJ (1998) Maternal vitamin use, genetic variation of infant methylenetetrahydrofolate reductase, and risk for spina bifida. Am J Epidemiol 148(1):30-37

Shields DC, Kirke PN, Mills JL, Ramsbottom D, Molloy AM, Burke H, Weir DG, Scott JM, Whitehead AS (1999) The "thermolabile" variant of methylene tetrahydrofolate reductase and neural tube defects: an evaluation of genetic risk and the relative importance of the genotypes of the embryo and the mother. Am J Hum Genet 64(4):1045-1055

Silva LM, Silva JN, Galbiatti AL, Succi M, Ruiz MT, Raposo LS, Maniglia JV, Pavarino-Bertelli EC, Goloni-Bertollo EM (2011) Head and neck carconogenesis: impact of MTHFD1 G1958A polymorphism. Rev Assoc Med Bras 57(2):194-199

Silva-Zolezzi I, Hidalgo-Miranda A, Estrada-Gil J, Fernandez-Lopez JC, Uribe-Figueroa L, Contreras A, Balam-Ortiz E, del BosquePlata L, Velazquez-Fernandez D, Lara C, Goya R, HernandezLemus E, Davila C, Barrientos E, March S, Jimenez-Sanchez G (2009) Analysis of genomic diversity in Mexican Mestizo populations to develop genomic medicine in Mexico. Proc Natl Acad Sci USA 106(21):8611-8616. doi:10.1073/pnas.090304 5106

Stevens VL, Rodriguez C, Sun J, Talbot JT, Thun MJ, Calle EE (2008) No association of single nucleotide polymorphisms in one-carbon metabolism genes with prostate cancer risk. Cancer Epidemiol Biomarkers Prev 17(12):3612-3614. doi:10.1158/ 1055-9965.EPI-08-0789

Toole JF, Malinow MR, Chambless LE, Spence JD, Pettigrew LC, Howard VJ, Sides EG, Wang CH, Stampfer M (2004) Lowering homocysteine in patients with ischemic stroke to prevent recurrent stroke, myocardial infarction, and death: the Vitamin Intervention for Stroke Prevention (VISP) randomized controlled trial. JAMA 291(5):565-575. doi:10.1001/jama.291.5.565

Urano W, Taniguchi A, Yamanaka H, Tanaka E, Nakajima H, Matsuda Y, Akama H, Kitamura Y, Kamatani N (2002) Polymorphisms in the methylene tetrahydrofolate reductase gene were associated with both the efficacy and the toxicity of methotrexate used for the treatment of rheumatoid arthritis, as evidenced by single locus and haplotype analyses. Pharmacogenetics 12(3): 183-190

Weisberg I, Tran P, Christensen B, Sibani S, Rozen R (1998) A second genetic polymorphism in methylene tetrahydrofolate reductase (MTHFR) associated with decreased enzyme activity. Mol Genet Metab 64(3):169-172. doi:10.1006/mgme.1998.2714

Wilcken B, Bamforth F, Li Z, Zhu H, Ritvanen A, Renlund M, Stoll C, Alembik Y, Dott B, Czeizel AE, Gelman-Kohan Z, Scarano G, Bianca S, Ettore G, Tenconi R, Bellato S, Scala I, Mutchinick OM, Lopez MA, de Walle H, Hofstra R, Joutchenko L, Kavteladze L, Bermejo E, Martinez-Frias ML, Gallagher M, Erickson JD, Vollset SE, Mastroiacovo P, Andria G, Botto LD (2003) Geographical and ethnic variation of the $677 \mathrm{C}>\mathrm{T}$ allele of 5,10 methylenetetrahydrofolate reductase (MTHFR): findings from over 7000 newborns from 16 areas world wide. J Med Genet 40(8):619-625

Wilson CP, Ward M, McNulty H, Strain JJ, Trouton TG, Horigan G, Purvis J, Scott JM (2012) Riboflavin offers a targeted strategy for managing hypertension in patients with the MTHFR 677TT genotype: a 4-y follow-up. Am J Clin Nutr 95(3):766-772. doi:10.3945/ajcn.111.026245

Wilson CP, McNulty H, Ward M, Strain JJ, Trouton TG, Hoeft BA, Weber P, Roos FF, Horigan G, McAnena L, Scott JM (2013) Blood pressure in treated hypertensive individuals with the MTHFR 677TT genotype is responsive to intervention with riboflavin: findings of a targeted randomized trial. Hypertension 61(6):1302-1308. doi:10.1161/HYPERTENSIONAHA.111. 01047 
Wolff T, Witkop CT, Miller T, Syed SB (2009) In: Folic acid supplementation for the prevention of neural tube defects: an update of the evidence for the U.S. preventive services task force. U.S. Preventive Services Task Force evidence syntheses, formerly systematic evidence reviews. Rockville (MD)

Xie H, Guo J, Wang J, Wang F, Zhao H, Liu C, Wang L, Lu X, Wu L, Bao Y, Zou J, Zhang T, Niu B (2012) Glutamate carboxypeptidase II gene polymorphisms and neural tube defects in a highrisk Chinese population. Metab Brain Dis 27(1):59-65. doi:10. 1007/s11011-011-9272-8

Yafei W, Lijun P, Jinfeng W, Xiaoying Z (2012) Is the prevalence of MTHFR C677T polymorphism associated with ultraviolet radiation in Eurasia? J Hum Genet 57(12):780-786. doi:10.1038/jhg. 2012.113

Yan L, Zhao L, Long Y, Zou P, Ji G, Gu A, Zhao P (2012) Association of the maternal MTHFR C677T polymorphism with susceptibility to neural tube defects in offsprings: evidence from 25 case-control studies. PLoS ONE 7(10):e41689. doi:10.1371/ journal.pone.0041689
Yang B, Liu Y, Li Y, Fan S, Zhi X, Lu X, Wang D, Zheng Q, Wang Y, Sun G (2013) Geographical distribution of MTHFR C677T, A1298C and MTRR A66G gene polymorphisms in China: findings from 15357 adults of Han nationality. PLoS ONE 8(3):e57917. doi:10.1371/journal.pone.0057917

Yu K, Zhang J, Zhang J, Dou C, Gu S, Xie Y, Mao Y, Ji C (2010) Methionine synthase A2756G polymorphism and cancer risk: a meta-analysis. Eur J Hum Genet 18(3):370-378. doi:10.1038/ ejhg.2009.131

Zeisel SH (2011) The supply of choline is important for fetal progenitor cells. Semin Cell Dev Biol 22(6):624-628. doi:10. 1016/j.semcdb.2011.06.002

Zhou D, Mei Q, Luo H, Tang B, Yu P (2012) The polymorphisms in methylenetetrahydrofolate reductase, methionine synthase, methionine synthase reductase, and the risk of colorectal cancer. Int J Biol Sci 8(6):819-830. doi:10.7150/ijbs.4462 